\title{
FROM VIRTUAL TO MATERIAL RESTORATION. A PROPOSAL FOR THE REASSEMBLY OF THE ALTAR OF THE HOLY HEART OF MARY IN THE CATHEDRAL OF SANTA MARIA ASSUNTA IN GERACE (REGGIO CALABRIA, ITALY)
}

\author{
F. Prampolini ${ }^{\text {a }}$, A.M. Oteri ${ }^{\text {a }}$, S. Caporale ${ }^{\text {a }}$, S. Mazzeo ${ }^{\text {a }}$, F. Muscherà ${ }^{\text {a }}$ \\ ${ }^{a}$ Mediterranea University of Reggio Calabria, PAU, Salita Melissari, 89124 Reggio C. (Italy) \\ franco.prampolini@unirc.it annunziata.oteri@unirc.it; \\ stefaniac24@gmail.com francesca.muschera@libero.it mazzeosara.90@libero.it
}

KEY WORDS: Digital survey, virtual restoration, altar, reassembly, authenticity, photomodelling.

\begin{abstract}
:
The present study explores the relationship between the new frontiers of architectural survey and architectural restoration. The result is a project for the reassembly of the Altar of the Holy Heart of Mary in the Cathedral of Gerace, in the province of Reggio Calabria. It was dismantled in the last century with the purpose to restore the "solemn and sober aspect" of the church during the medieval age. The idea was born in the sphere of a multidisciplinary didactic experience, which involved history, conservation, digital modelling, design and enhancement of cultural heritage. The process, from analyses to project, followed four steps: realization of a systematic photogrammetrical survey of each architectural element of the 18th century altars of the cathedral, which were dismantled in the last century, with high precision photomodelling techniques; early identification of the single objects, positioning structured QR-CODE with metadata and short description directly in the shooting phase; pre-cataloguing phase, implemented by the compilation of single cards regarding each piece, using a redrafted version of the ICCD OA card (artwork 3.00 version); a proposal for the reassembly of the altar of the Holy Heart of Mary. The reassembly is conceived as an alternative to the reconstruction of the altar "as it was", using a steel structure that is partially visible, which was studied to support and "exhibit" the marble pieces. The availability of numerical models for each piece facilitated, on one side, weight distribution analysis and, consequently, correct dimensioning of the support structure and, on the other side, interactive simulation processes for design optimisation and aesthetic evaluation.
\end{abstract}

\subsection{Introduction}

The relationship between new frontiers of architectural survey and architectural restoration is controversial. The significant evolution of survey techniques in the field, with the introduction of digital methods and, more in general, the increasing use of Information and Communication Technologies (ICT) techniques in the field of conservation, facilitates the study and monitoring of historical buildings. Time for survey and elaboration is significantly reduced and levels of detail and precision in gathering and processing information are considerably improving.

Digital survey permits accurate analyses of the studied element (regardless of the scale: a marble piece, a structural element, a building, an urban area), examining in depth dimension, shape, building materials, constructive techniques, traces of decay and so on. Unlike traditional methods, innovative techniques also permit to analyse inaccessible parts of buildings, archaeological sites, and urban fabric.

However, as often happens when different subjects meet in a common field, it is very difficult to find agreement on the main purpose of innovative strategies (Treccani, 2013). In the case of architectural restoration, for example, a cognitive approach entirely based on digital information is not acceptable. Digital photogrammetry, for example, based on image-based modelling permits to elaborate a mimetic representation of the object, as in the case here presented. The amount of data (information) which can be gathered with this method and the great precision in elaboration is impressive. However, historical buildings and, more in general, cultural heritage is the result of many transformations over time, and each sign it preserves holds meanings (and values) which are strictly related to the history of the people and societies who used it from the origin to present day. For this reason, data in themselves are mute, they do not tell any story. They need to be filtered by the personal cognitive experience of the studied object. In this sense, and always with a critical approach, a phase of interpretation which relates all the information recorded (dimension, shape, building materials, decay processes and so on) with the historical and environmental background of the object (Acierno, 2017) is required. Therefore, the aim of the analyses is not the representation of the object as it could be in the future. On the contrary, based on the idea that intervention (restoration, maintenance, monitoring, and so on) aims to preserve the material authenticity of the object, digital survey can be very useful when the model helps in representing, with great accuracy, its real condition (the single architectural element, the historic building, the site, etc.) (Fiorani, Acierno, 2016). The question is far from being solved, as, in general, the purpose of intervention and, as a consequence, of thee cognitive approach is far from being defined. If data are mute (they do not tell the history of the object they record) they are, at the same time, not neutral (Settis, 2002); it means that, in the phase of interpretation, they can be manipulated (or misinterpreted) and lead the project in a wrong direction. For this reason, it is of utmost importance to define the objective of the intervention from the beginning and, also, the role and the significance that one assigns to the phase of data collection. If the objective is, as in the case here studied, a transformation which preserves, as much as possible, what remains, digital survey and data cataloguing should be used not just as tools which orient the project but as instruments for modelling and representing reality. On the contrary, when the objective of intervention is the 
reconstruction of how the object was in the past or how it could be in the future, digital survey, and, more in general, the cognitive approach, becomes an operative instrument which manages the project.

Certainly, the possibility to reproduce, rapidly and in detail, the original aspect of what is now fragmented, decaying or in ruin, is an irresistible temptation for those who work in both the field of survey and restoration. This is the reason why, in the last few years, the experiences of virtual restoration or augmented reality have increased enormously, and very often replace material restoration. There is no archaeological site or museum that is not provided with a computer placement which permits visiting the site as it was centuries and centuries ago, or walking around the exhibition rooms without moving a step. This revolution involved a significant change in the experience of architectural heritage, also in terms of fruition and interactivity between subject and object (Sulfaro, 2011). But they are practices which, despite appearances, increase the distance, as users are put in contact not with the real object but with a representation, as precise as possible but immaterial, of it.

Therefore, a final reflection regards some misunderstandings which virtual or immaterial restoration could generate. In recent times, virtual reconstructions or experiences of augmented reality have very often replaced material restoration. The idea which strengthens these new practices is that, by doing so, and fully respecting what remains (the object is not directly modified by the intervention) one can give the perfect (or presumed) idea of what the object was in the past. Of course, these kinds of operations generate a deep emotional impact on common people, who can experience the object without knowing anything about it. Apart from cultural aspects (concepts such as culture and entertainment, which have two very different meanings, are often confused), another important question arises in terms of method: virtual restoration inhibits the possibility of finding proper solutions in the field of material restoration. A sort of principle of non-responsibility develops which, in the name of respect of object integrity, renounces the design of a tangible but respectful intervention in favour of immaterial and often incorrect reconstructions. Doing so, one frequently forgets that preserving and enhancing what remains is a valid alternative to debatable virtual reconstructions and/or tangible but false reproductions of what the object was. The present study and the resulting application - the reassembly of the altar in the Cathedral of Gerace - aims to follow this principle.

\subsection{Some notes on the history of the Cathedral}

The history of the Cathedral of Gerace, originally founded in the 11 th century, is characterized by significant destructions and transformations over time, in part due to the many earthquakes which struck the area and in part to some "unexpected" changes in aesthetic thought, or to misinterpreted ideas of restoration over time that, especially in the 20th century, which significantly altered the interior of the church with the purpose of restoring the "solemn and sober aspect" of the medieval age ${ }^{1}$. The altar of the Holy Heart of Mary, like many other eighteenth-century altars in the church, was the "sacrificial victim" of this significant process of stylistic restoration. It was built in 1771, in the left apse of the cathedral, by master artisans of the Neapolitan school and was disassembled between 1949 and 1951 during the interventions of restoration directed by Gisberto Martelli, with the aim to dismantle the "Baroque" internal aspect of the church and revive the supposed medieval aspect.

${ }^{1}$ On the history of the Cathedral of Gerace see Cagliostro, 2002; Gemelli et al., 1996; Occhiato, 1973-1974; Valtieri 2002; Zinzi, 1991.

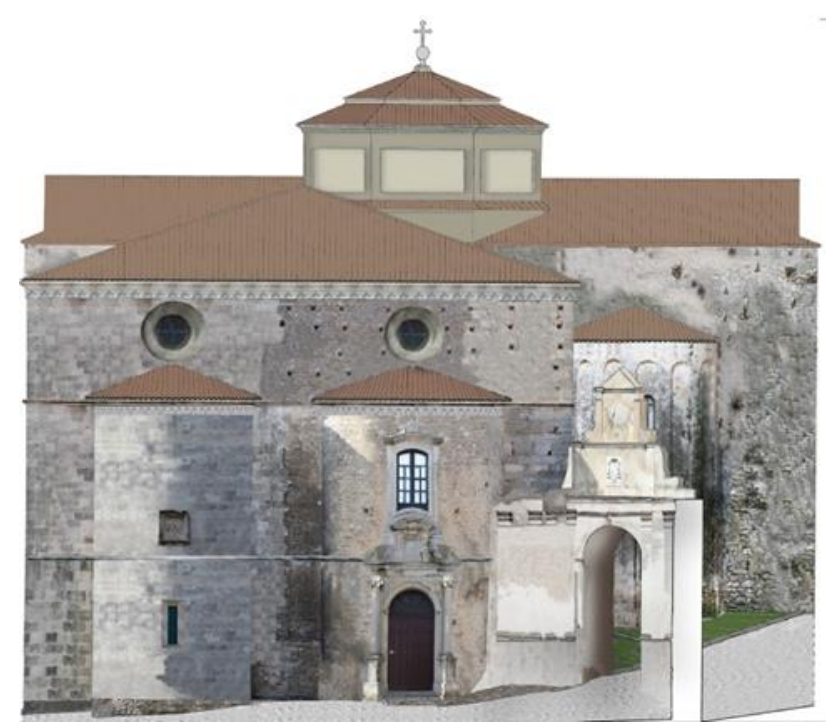

Figure 1. Digital reconstruction of the apses prospect
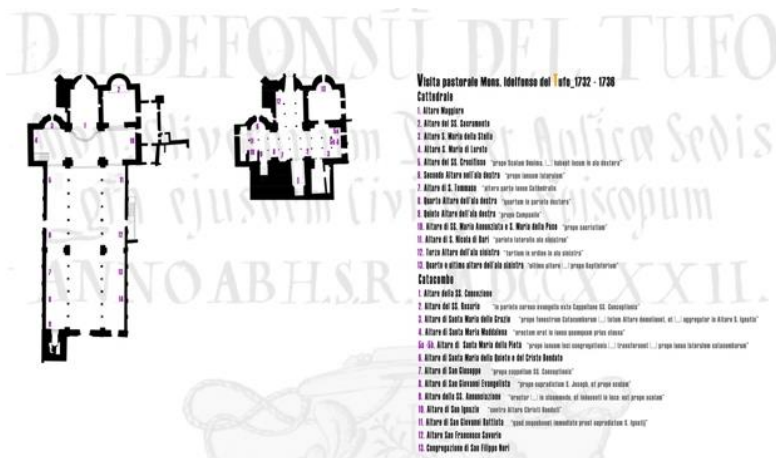

Figure 2. Hypothesis of the original placement of the altars according to the reports of pastoral visits of Mons. Idelfonso del Tufo

The original marble blocks, which did not remain in place, were scattered all around the place, some in several underground storehouses of the cathedral itself, some around the site, even in open unattended places where they still remain today.

Historical analyses documented that in 1541 an altar dedicated to SS. Salvatore, then restored in 1600 , already exited in the left apse of the cathedral. In the pastoral visit of 1732, Monsignor Idelfonso Del Tufo named the altar as Saint Mary of the Star. It is not clear if the altar was then destroyed and reconstructed or if only the name was changed, but in 1752 it reappeared as the altar of SS. Salvatore ${ }^{2}$ (Gemelli, 1973). The information on the history of the altar is fragmentary but it is clear that only in the nineteenth-century was it dedicated to the Holy Heart of Mary (Oppedisano, 1932). Bibliographic and archival analyses also gave useful information on the altars existing in the cathedral before the dismantling, providing each dedication and a significant description. It was so possible to suppose where altars were located in the naves over time.

Crossing the data derived from digital survey with historical analyses it was possible to identify, among nearly 150 marble pieces, those which belonged to the altar of the Holy Heart of Mary.

A picture of the altar in the 1940's (which shows what it was like immediately before the dismantling), found during the archival research, was essential for the elaboration of the project of

${ }^{2}$ Pastoral visit of Idelfonso del Tufo are in National Archive of Locri (RC), Gerace collection, vol. 14. 
reassembly (fig. 1). Thanks to this picture, and with the help of high-precision photomodelling techniques, it was possible to identify 24 the marble elements belonging to it with a very high degree.

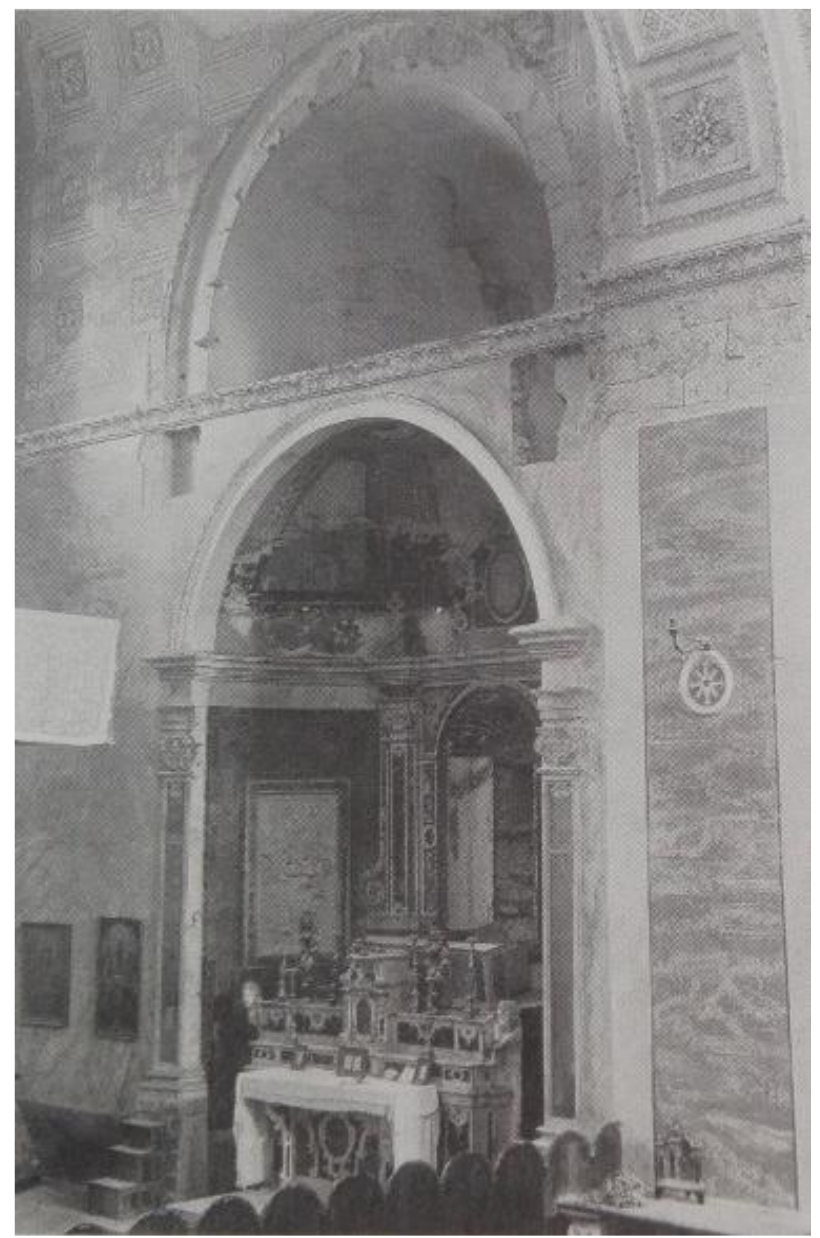

Figure 3. The altar of the Holy Heart of Mary still in situ, before the dismounting, in the left apse of Gerace Cathedral (1934).

\subsection{The survey campaign}

The didactic experience was developed within a wider "happening" called "Un estate di arte e fede nella Diocesi di Locri-Gerace" (Art and faith summer in the Dioceses of LocriGerace), which involved the Diocese of Locri-Gerace itself as promoter, the Department of Heritage, Architecture, Urban Planning (PAU) of the University Mediterranea of Reggio Calabria, the Superintendence for Cultural Heritage and Landscape of Reggio Calabria and private initiatives, with the purpose to gather students, scholars, restorers, local policy makers, etc., to share disciplines and "practice on site" to study and enhance historic and artistic local heritage.

The project was organised as an "open laboratory of architectural restoration", located within the cathedral and open to the public, to recover and study the over 150 discovered disassembled pieces belonging to the eighteenth-century altars which were inside the church before the above mentioned dismantling. To facilitate the study and classification, each element was previously slightly restored (cleaning and some provisional interventions).

After this phase, under the supervision of the authors, a group of students realized a systematic photogrammetrical survey of each architectural element with photomodelling techniques, leading to geometric precision and accuracy, along with descriptive details, up to a $1: 1$ scale.

Considering the particular nature of the objects, absolute georeferencing of the single pieces was not considered relevant, although the geographical coordinates (referred to the centroid of the cathedral as a whole) were recorded for compliance with general cataloguing standards.

The early identification of each single object has been guaranteed by a structured QR-CODE with technical and administrative information.

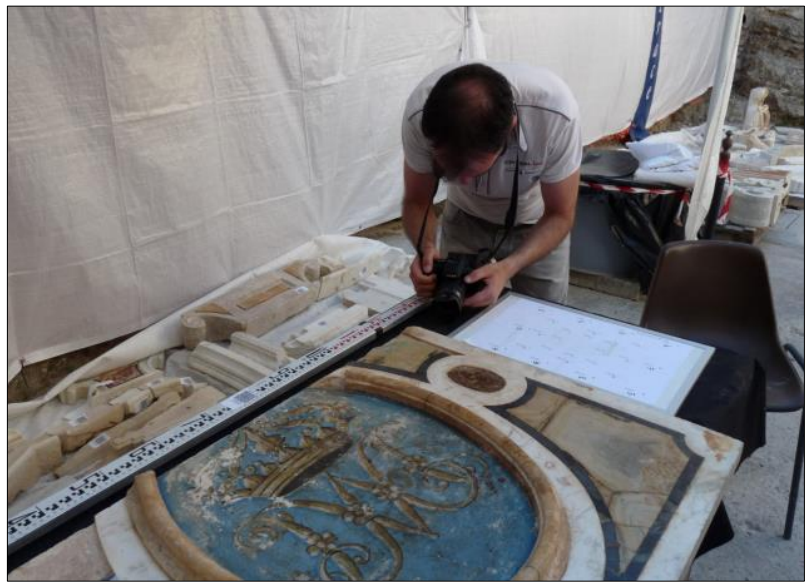

Figure 4. A moment of the survey.

The models were realized at the maximum compatible resolution. Obviously, it's still possible to make a subsequent selection of geometric information by decimating and editing the meshes or to export them in different formats suitable for most 3D modelling software for post processing.

The pre-cataloguing phase was implemented by the compilation of single catalog cards regarding each piece of the altars using a redrafted version of the $\mathrm{ICCD}^{3} \mathrm{OA}$ card (artwork 3.00 version).

\subsection{Photogrammetry}

The survey involved the 154 marble pieces, recovered from the cave underneath the crypt, a dozen more different marble orphans laying all around the cathedral and, naturally, the left apse still hosting the altar base left in place after the final dismantling of the baroque superstructure.

Each piece has been photographed trying to build up the maximum possible coverage and detail. Due to the particular situation and the short time available, we decided to overdimension the coverage itself, ending up to a, maybe, redundant scheme. At the conclusion of the campaign, over 36.000 frames have been counted, and even the smallest and, apparently, insignificant piece has been documented by more than one hundred photos.

This number of frames could be considered, somehow, overdone, but it proved, indeed, very useful in the subsequent modelling step, allowing to overcome some well-known problems arising in this phase for the recognition of very homogeneous surfaces. To achieve better results from the chromatical point of view the photographic set was settled outdoor, under a thick white curtain allowing a diffuse illumination (no shadows), an easy white balance setting and, finally, a very natural effect in reproducing colours for texturing.

\footnotetext{
${ }^{3}$ Central Institute for Cataloguing and Documentation.
} 


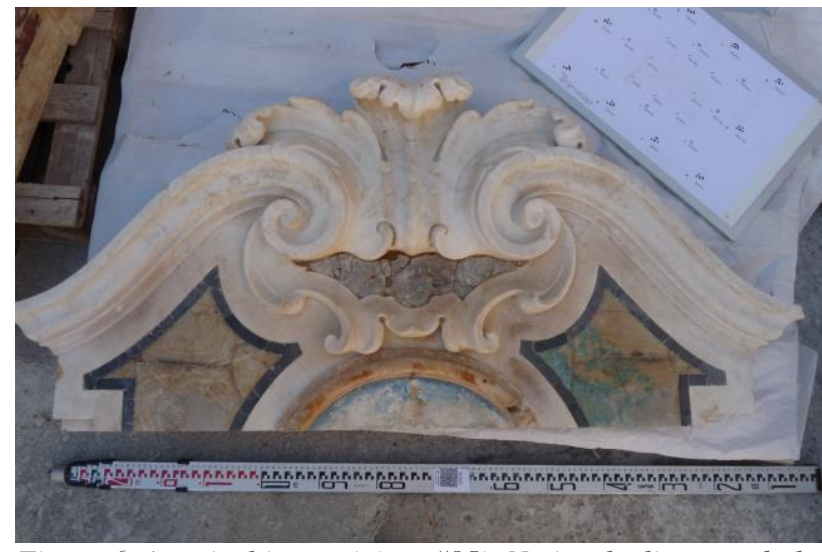

Figure 6. A typical image (piece \#85). Notice the linear rod, the $Q R$-Code with references and metadata and the calibrated grid.

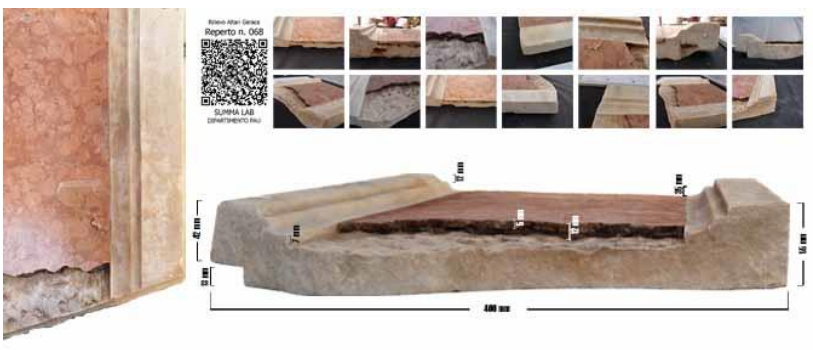

Figure 5. Dimensioned 3D model of a piece

This was considered a major problem foreseeing the difficulties that could arise in the subsequent comparison of the different pieces, aimed at the typification and recognition of the individual fragments. Furthermore, the exposure time, even with a very narrow aperture of the diaphragm in order to increase depth of field, could be held fast enough to allow freehand shooting, so reducing times impressively.

The photo shoots were immediately followed, on site, by a first elaboration intended to verify the completeness of the overall coverage, and the individual piece returned to the care of the restorers.

Final modelling was preceded by a systematic masking activity, requiring a great effort in terms of time, but necessary to obtain better and more accurate results.

The models were scaled using both the simple linear approach, including a topographic rod in images, and a more complex one using a calibrated grid realised with markers of known coordinates that can be automatically detected by the modelling software itself.

The final results, in terms of precision, are quite satisfactory. The average residuals remained in the sub-millimeter range, so reaching significance in that one-to-one territory that, formerly, Jorge Luis Borges described in his famous short tale On Exactitude in Science, (significantly placed in the collected tales of the Universal History of Iniquity) where the cartographers of the empire had drawn up a map so detailed that, at the end, it came to be exactly coincident with the empire itself and it was considered completely useless by the inhabitants that, not without some pitilessness, abandoned it at the mercy of Animals and Beggars. Of course we do not dare to derive philosophical results from these considerations, but, maybe, following Baudrillard ${ }^{4}$ words, it has come a time where, contrariwise, occasionally ... it is the territory itself whose shreds slowly rot across the extent of the map. It is the real, and not the map, whose vestiges persist here and there in the deserts that are no longer those of the Empire, but ours. The desert of the real. As a matter of fact, in our view, the one to one scale does not mean exact coincidence, but just identifies the significance of the precision reached in terms of metrical and descriptive accuracy.

As a final result, anyway, each piece has been fully documented with photomodelling techniques. The models are now available in the native software format and in the different most popular standards for 3D frameworks, such as OBJ, WRL, 3D-PDF, etc. to be used for any subsequent elaboration or further evaluation. Photogrammetry extends the measurability of the objects to the continuum of their photographic image and thus enables the creation of models which are useful for their immediate finalization, but, at the same time, suitable for different purposes, eventually arising, that might not preliminarily be determined. The availability of these very detailed models, however, does not wither the thought, but, on the contrary, opens new spaces to reason and to the ability of "storytellers". Digital models, indeed, do not just guarantee "technical support" for design activities, but enable simulation processes that cannot be possibly activated otherwise.
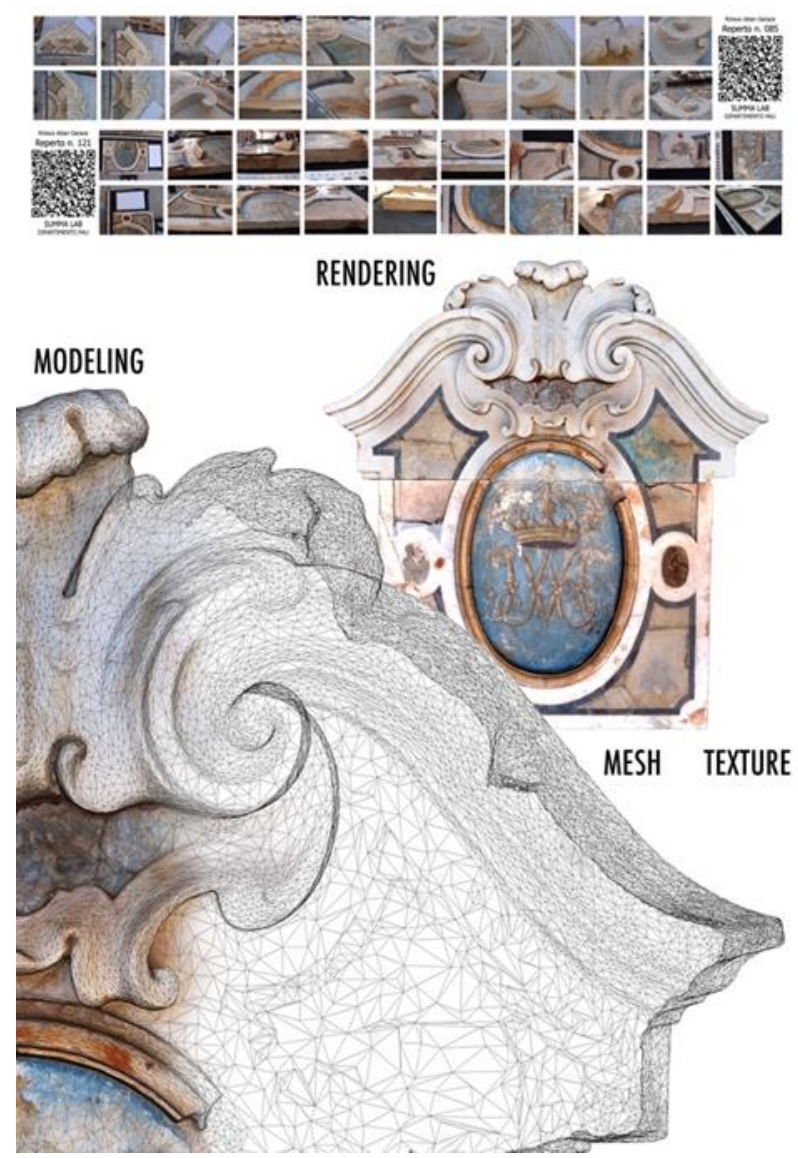

Figure 7. Re-elaboration of the crowning gable end of the altar.

\subsection{Cataloguing}

As mentioned above, each piece was then catalogued using cards compliant with the ICCD Standards.

The structure of the database is designed to ensure a perfect correspondence between each field of the data base itself and the ICCD specifications. The current cards are built as a "subset" of

\footnotetext{
${ }^{4}$ Baudrillard, 2008
} 
the main ICCD reference, but they still contain all the main data, such as codes (card id, QR-CODE, administrative references, etc.), object data, geocoding general data, chronology, definition, description, technical data, state of conservation, possible restrictions, archival documentation, and so on. Furthermore, they add some augmented flexibility to the original cards to deal with large datasets of images and the capability to handle models directly by $3 \mathrm{D}$ viewers, while maintaining direct one-to-one compatibility with ICCD formats.

Particular attention has been dedicated to the description of every single item, both from the point of view of the controlled vocabularies of cataloguing standards, and from that of historical critique.

The card has been implemented in Microsoft Access and, noticeably, allows, aside from the usual queries, direct exploration of the 3D models and the connected visual information.

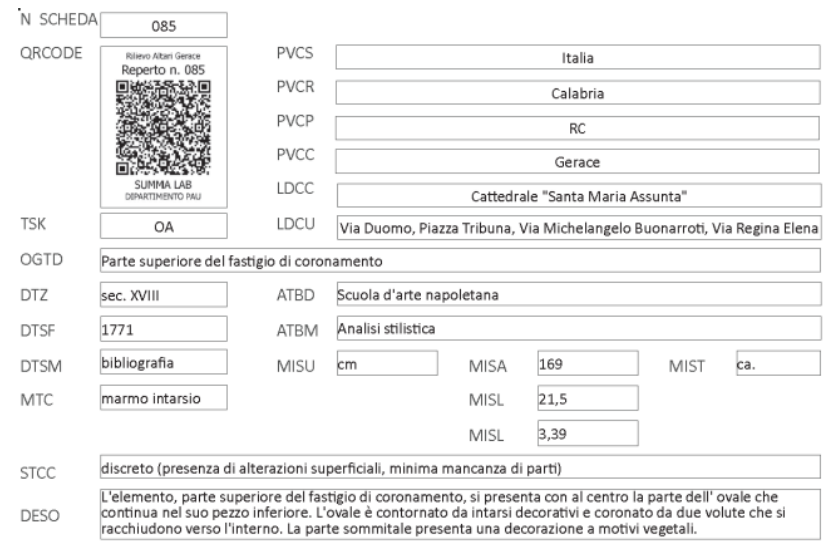

Figure 8. A detail of the catalog card.

\subsection{The project of reassembly}

The project for the reassembly of the altar is a stimulating occasion to face the issues relating to cognitive innovative approaches and designs for conservation. Accurate field and archive research made it possible to identify up to 24 significant single pieces that, with a very high degree of likelihood, were part of the original altar, allowing us to pre-evaluate the technical and speculative implication of the project, as a whole. Although the missing $f$ are many more than the rescued ones, the final effect of verisimilitude is allowed.

A first option considered reassembling the altar in another location, e.g. the neighbouring Museo Diocesano. However, from prior analyses, difficulties of such an operation emerged. Reassembly in real scale requires an appropriate environment in terms of dimension, not to mention the suitability of perceptual space. Furthermore, the risk of failure of the operation, due to rebuilding out of the original context was relevant. The idea to reassemble the original marble pieces of the altar in the original site was also supported by the fact that, in the process of dismantling, the altar table was preserved and is still present in the left apse. From the evaluation of all these aspects, the idea stemmed to propose the reassembly in the original site. The main principle supporting the project was to totally respect what remains of the original structure (the altar table still in situ and the marble pieces to be reassembled in the initial position). Therefore, the main aim was to preserve the authentic building materials trying to design new elements (the frame to support the marble pieces) which do not overwhelm the original parts, mainly under the conceptual point of view.

The reassembly is conceived as an alternative to the reconstruction of the altar "as it was", using a very light steel structure that is partially visible, which was studied to support and "exhibit" the marble pieces.

The availability of numerical meshed and solid models for each piece facilitated weight distribution analysis and, consequently, correct dimensioning of the support structure, having the total weight (assuming conventional values for the s.g. of the marble),
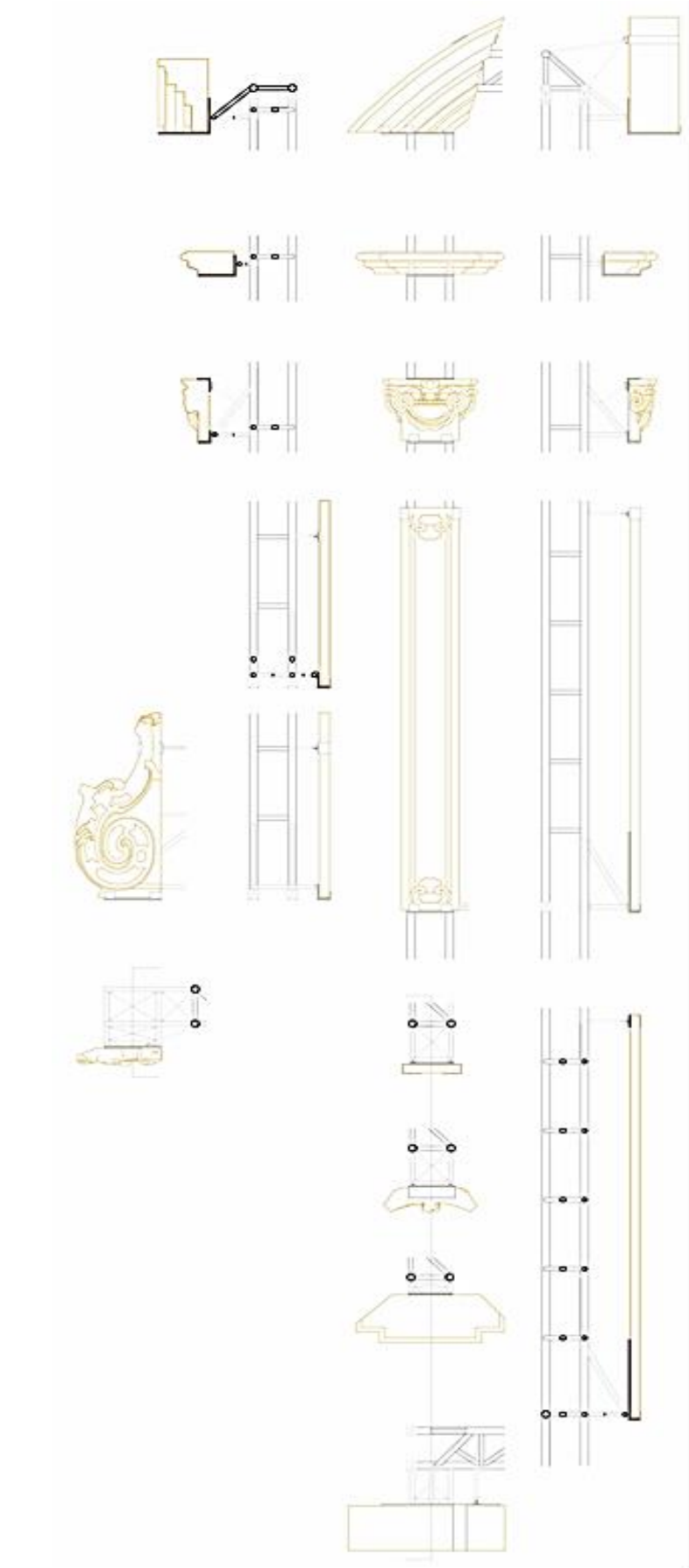

Figure 9. Details of the mounting structure.

the barycentre and the spatial distribution of the moments of inertia of each piece, mainly depending on the irregular, different shapes, immediately available. 


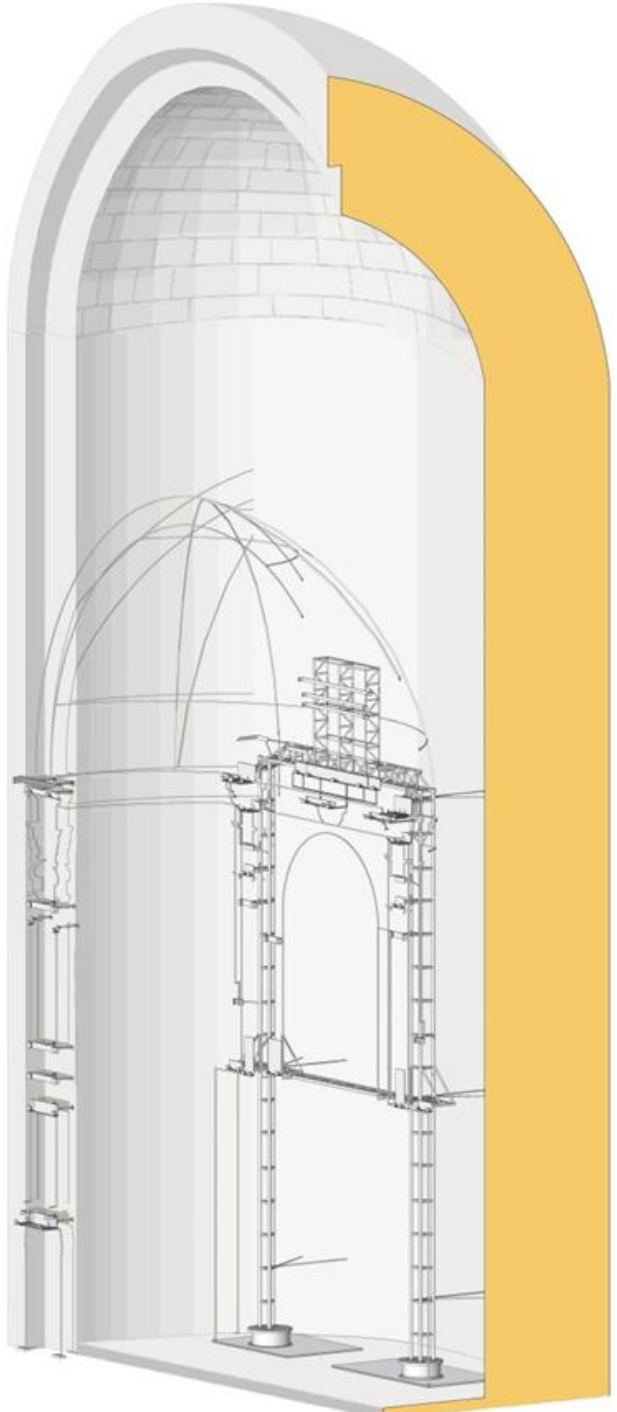

Figure 10. View of the mounting structure positioned in the apse.
The possibility to reach a total visual control of each piece, together with the high resolution of the models, helped in the design of the support elements for the marble pieces, which resulted in highly detailed, including support brackets, wall connection, and so on.

Finally, following the idea of maximizing respect for the existing parts without renouncing a suggestion of the original unity of the altar and the chapel, the missing pieces are reminded by styled wire elements connected to the marble blocks.

\subsection{Conclusions}

Talking about photogrammetry, photomodelling, digital approach, simulation, virtuality, may seem today a sort of commonplace. They are, indeed, tools lying on the table right in front of us, available, now even unencumbered from the burden of high costs and the need for some too highly specialized personnel. But nothing can ever be said to be obvious until it is actually applied in everyday life. The use of these techniques, despite all, is still limited to specialists.

It is probably time, bearing in mind, for example, the laws that are making it the use of the Building Information Management (BIM) approach compulsory in public sector planning, to extend, spread and, somehow, force the use of rigorous surveying methodologies in design and conservation activities for cultural heritage. This would probably still require a lot of work, in the reciprocal education, for students, scholars, public officers engaged in the protection and enhancement of cultural heritage, restoration specialists, policy makers, local and global stakeholders, and so on, hopefully focusing on the most productive ways of on job engagement. This will generate, and this is what has happened last summer in Gerace, a great deal of something that we can call social and cultural empowerment.

This approach can open wide spaces to a highly characterised synthesis, as we introduced at the beginning of this work, between tangible and respectful intervention and the digital approach, avoiding the perils and pitfalls of self-referential virtuality, but not without the irreplaceable support of new technologies.

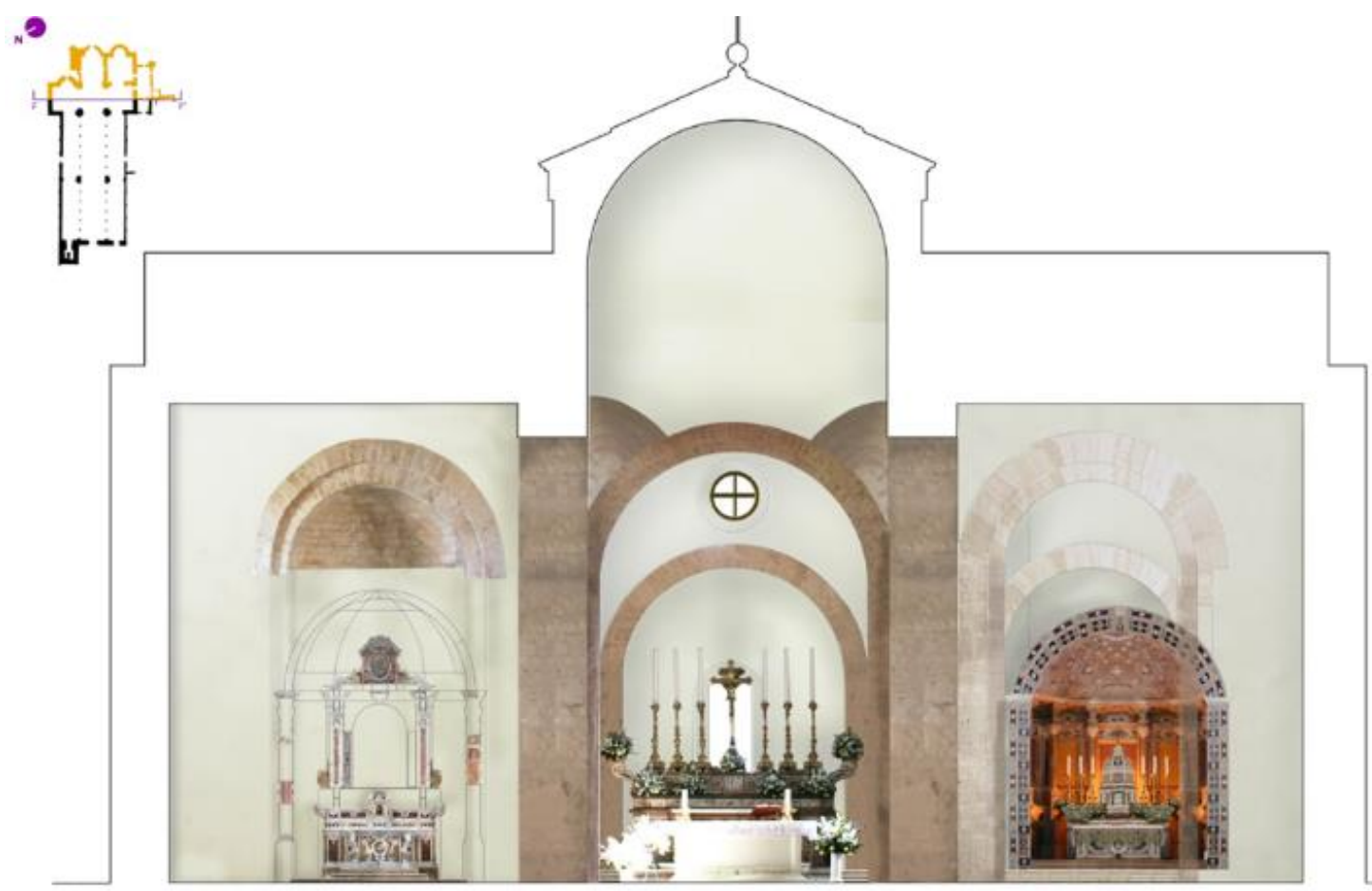

Figure 11. Cross-section of the transept of the cathedral with three apses 


\section{REFERENCES}

Acierno M., Processi di studio per il restauro e metodi digitali, in Ricerca/Restauro, coordinamento D. Fiorani, sez. 4, Valorizzazione e gestione delle informazioni, a cura di R. Prescia, Quasar, Roma 2017, pp. 838-848.

R. M. Cagliostro (A CURA DI) Atlante del Barocco in Italia Calabria, De Luca Editori D’Arte, Roma 2002

Fiorani D., Acierno M., Drawing, information and design: Tools and perspectives for conservation, in Ippolito A., Cigola M. (edit by), Handbook of research on Emerging Technologies for Architectural and Archaeological heritage, IGI-global, Hershey (Pennsylvania, USA) 2016, pp. 355-386.

Fiorani D., Materiale/immateriale: frontiere del restauro, in "Materiali e strutture", 2014, 5-6, pp. 9-23.

Gemelli S., L'altare del SS. Salvatore nella Cattedrale di Gerace, in «Calabria Turismo», XV (1973), pp. 67-69.

Gemelli S. et al., La Cattedrale di Gerace. Il monumento, le funzioni, i corredi, Cassa di Risparmio di Calabria e Lucania, Cosenza 1996.

Occhiato G., 1973-1974|, Per la storia del ripristino della Cattedrale Normanna di Gerace, in "Archivio Storico per la Calabria e la Lucania”, XLI (1973-1974), pp. 87-111.

Oppedisano A., Cronistoria della diocesi di Gerace, Tipografia Isidoro Cavallaro, Gerace 1932.

Treccani G.P., Innovazione e tradizione. Pratiche del restauro a venire, in Musso S. (edited by), Tecniche di restauro. Aggiornamento, Utet, Torino 2013, pp. 103-143.

Settis S., L'illusione dei beni digitali, in "Bollettino ICR", 2002, 5, pp. 18-20.

Sulfaro N., Il passato non è più quello di una volta. La fruizione ai tempi del Web 2.0, in G. BISCONTIN, G. DRIUSSI (a cura di), Governare l'innovazione. Processi, strutture, materiali e tecnologie tra passato e futuro, Atti del XXVII Convegno Scienza e Beni Culturali (Bressanone, 21-24 giugno 2011) Arcadia Ricerche, Venezia 2011, pp. 553-562.

Valtieri S. (edited by), Cattedrali di Calabria, Gangemi Editore, Roma 2002, pp. 43-52.

Zinzi E., Vicende costruttive della Cattedrale di Gerace: Trasformazioni, alterazioni, restauri attraverso fonti archivistiche (secoli XVII-XX), in "Archivio Storico per la Calabria e la Lucania", LVIII (1991), pp. 85-100.

Baudrillard J., Simulacri e imposture, Pgreco, Milano 2008.
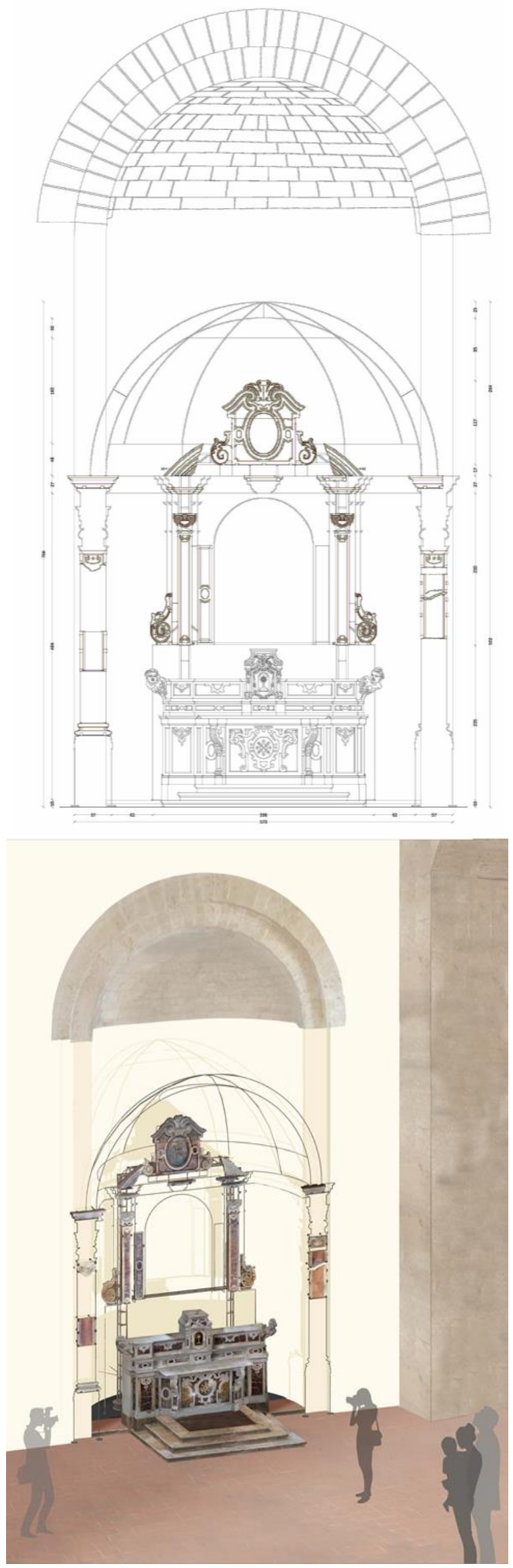


\section{ACKNOWLEDGEMENTS}

Gli altari della cattedrale di Gerace. Dal rilievo digitale al restauro: una proposta per il riassemblaggio dell'altare del Sacro Cuore di Maria.

Doctoral Thesis discussed on march 16, 2017 c/o Mediterranea University of Reggio Calabria - Dipartimento PAU (Dir. prof. Francesca Martorano).

Stefania Caporale, Sara Mazzeo, Francesca Muscherà (authors).

Prof. Annunziata Maria Oteri (supervisor),

Prof. Franco Prampolini (survey and modelling),

Prof. Paolo Fuschi (structures),

Prof. Tommaso Manfredi (historical researches).

\section{UN'estATE TRA ARTE E FEDE NELlA DiOCESI DI LOCRI-GERACE}

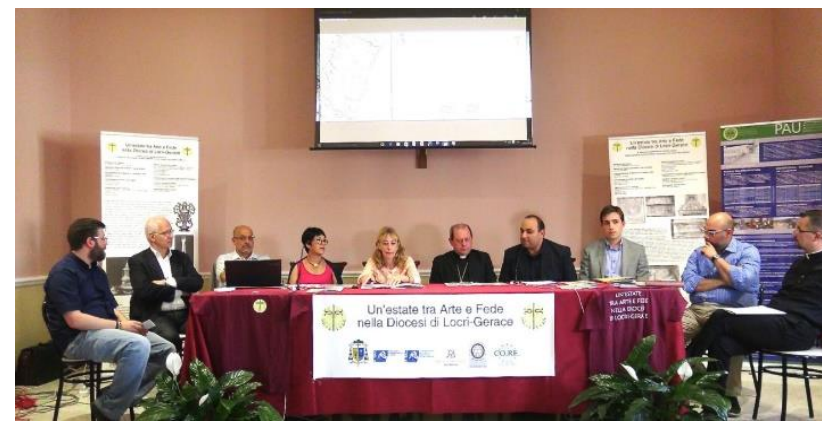

Figure 12. Introductory press conference, Gerace, July $4^{\text {th }}$, 2016.

\section{Partners:}

Diocesi of Locri-Gerace.

Special thanks to S.E. Mons. Francesco Oliva, don Fabrizio Cotardo and don Angelo Festa.

Giuseppe Mantella Restauri

General coordination of the project and the restoration Lab.

Dipartimento PAU - Università Mediterranea Reggio C.

Dir. prof. Francesca Martorano.

Coord. prof Franco Prampolini.

Technical tutoring: cons. Antonio Gambino, cons.Marilù Laface.

Soprintendenza per le Belle Arti e il Paesaggio della Calabria. Arch. Margherita Eichberg

Segretariato Regionale MiBACT per la Calabria. Dott. Salvatore Patamia

Comune di Gerace.
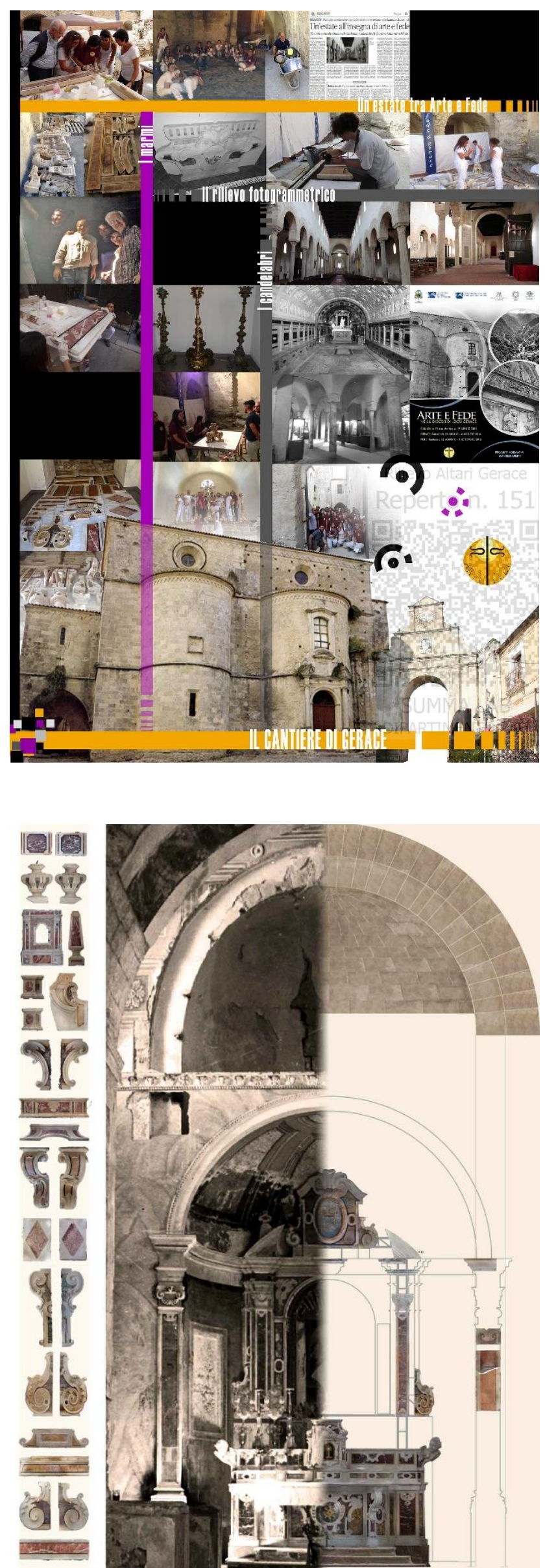